\title{
Panorama de los conflictos subnacionales en torno al agua en México. Aplicación de una propuesta metodológica para su identificación y caracterización
}

\section{Overview of sub-national conflicts over water in Mexico Application of a methodological proposal for its identification and characterization}

\begin{abstract}
Resumen
Los conflictos en torno al agua en México son un fenómeno que va en incremento. Sin embargo, existen diversos vacíos teóricos, conceptuales, de información y de políticas públicas que den cuenta de ello. Lo anterior se debe en parte a la casi nula existencia de estudios sistemáticos al respecto y de estadísticas que brinden información agregada sobre dicha problemática, ello como una vía de acción para su prevención y/o resolución. En ese sentido, en este trabajo se presenta una propuesta metodológica para la identificación, cuantificación y caracterización de los conflictos en torno al agua en México, enfocándose en los conflictos de índole subnacional o internos. Además, debido a que dicha metodología se aplicó en el país, se presentan los resultados obtenidos al respecto. Entre dichos resultados destaca la identificación y caracterización de casi 90 conflictos en torno al agua a lo largo y ancho del país.
\end{abstract}

Palabras clave: agua, conflictos sociales, tipologías, política hídrica, propuesta metodológica.
Rafael Ruiz Ortega•

Raúl Pacheco Vega*•

\begin{abstract}
Water conflicts in Mexico are an increasing phenomenon. However, there are various theoretical, conceptual information and public policy gaps that account for this. This is due in part to the almost null existence of systematic studies in this regard and statistics that provide aggregate information on this problem, as a way of action for its prevention and/or resolution. In this sense, this work presents a methodological proposal for the identification, quantification and characterization of conflicts around water in Mexico, focusing on conflicts of a sub-national or internal nature. In addition, as this methodology was applied in the country, the results obtained are presented. Among these results, the identification and characterization of almost 90 conflicts over water throughout the country stands out.
\end{abstract}

Keywords: water, social conflicts, typologies, water policy, methodological proposal.

\footnotetext{
- Doctor en Políticas Públicas por el Centro de Investigación y Docencia Económicas. Subdirector de Evaluación de Demandas en la Dirección Regional Noroeste del Consejo Nacional de Ciencia y Tecnología. rafaelruor@gmail.com—Orcid:0000-0003-25I I-8956.

- Phd, Resource Management and Environmental Studies (Political Science \& Human Geography), for the University of British Columbia. Profesor-investigador en el Centro de Investigación y Docencia Económicas. Departamento de Administración Pública. raul.pacheco-vega@cide.edu Orcid: 0000-0003-3468-5477.
}

Fecha de recepción: 6 de noviembre de 2020. Fecha de aceptación: 9 de marzo de 2021. 


\section{Introducción}

El agua es un recurso estratégico para el ser humano, lo cual, aunado a la creciente reducción de su disponibilidad, ${ }^{1}$ lo convierten en objeto de disputa constante, ya sea de manera directa o indirecta, generando la emergencia de conflictos sociales a diferentes niveles geográficos y con diferentes objetivos, llegándose incluso a vaticinar el surgimiento de guerras por el agua en diversos países (Yoffe $e t$ al., 2004; Selby, 2005; Kreamer, 2012; Gleick y Heberger, 2014; Moore, 2018). En el estudio de estos conflictos se ha privilegiado el análisis, evaluación y sistematización de información sobre conflictos de corte internacional, mientras que los conflictos de orden subnacional carecen de tal atención, cuando a decir de algunos autores, son los que se están presentando en mayor medida y con niveles de intensidad superior a los conflictos internacionales (Munk, 2004; Yoffe et al., 2004; Selby, 2005; IDEI, 2006; Mustafa, 2007; Gleick y Heberger, 2014).

México, aunque es un país que no sufre escasez hídrica al nivel de algunos países africanos y otros del Medio Oriente, no ha estado exento de este tipo de disputas. Diversos autores advierten que este fenómeno está creciendo y seguirá aumentando en los años venideros, incluso cada vez con mayor intensidad y complejidad (Ávila, 2002; Vargas y Mollard, 2004; Becerra, Sainz y Muñoz, 2006; Vargas, 2013; Pacheco-Vega, 2013 y 2014). A pesar de lo anterior, el estudio de los conflictos sociales subnacionales en torno al agua se encuentra subdesarrollado, existiendo diversas deficiencias que nublan un mayor entendimiento de este tipo de fenómenos sociales. Tales deficiencias se vislumbran

I. Entre los factores asociados a la reducción de su disponibilidad se encuentran, entre otros, la contaminación, el abatimiento de mantos acuíferos, el crecimiento poblacional y la demanda industrial. Todo esto impacta de alguna manera en la oferta y demanda del recurso, encareciendo su extracción y por lo tanto su costo. 
en la falta de estadísticas sistemáticas y fidedignas sobre estos conflictos en México; en la falta de consenso para su tipificación, clasificación e identificación; que ni en la academia ni en las políticas públicas mexicanas incidentes en el sector hídrico se vislumbran estudios sistemáticos para identificar y entender diversos aspectos asociados a estos fenómenos, que lleven a diseñar e implementar medidas de política pública integrales y efectivas para la prevención y/o tratamiento de dichos conflictos; entre otras.

A partir de una revisión documental profunda se pudo constatar que la mayor parte de los estudios que se han estado realizando obedecen a lógicas de casos, que si bien permiten profundizar en un conflicto específico, no permiten hacer conjeturas de carácter más amplio y general, ya sea para conocer su número y ubicación o para su caracterización; y a compilaciones de datos hemerográficos con diferentes escalas y metodologías que no permiten monitorear su evolución y/o comparar entre diversos casos en el país. Lo anterior, en parte se debe a que cada conflicto presenta características muy particulares, por lo que entender en profundidad cada uno de ellos requiere un gran esfuerzo de recopilación de información y análisis, resultando muy costoso estudiar un gran número de casos, y por otra parte, a que la operacionalización del fenómeno es aún poco clara. Sin embargo, a pesar de dichos obstáculos se considera que algunos comparten rasgos similares que pueden ser sistematizados.

Ante lo anterior, el objetivo de este trabajo es avanzar y aportar en tres aspectos. El primero de ellos es detallar el diseño de una metodología de identificación y recolección de datos sistemáticos sobre conflictos subnacionales en torno al agua, misma que retoma aspectos de anteriores trabajos al respecto. En segundo lugar, se explica la aplicación de dicha metodología en el caso de México y se exponen descriptivamente diversas estadísticas obtenidas relacionadas 
con características de 89 conflictos que a diciembre de 2015 y enero de 2016 se identificó que se encontraban activos en el país, resaltando aspectos como su duración, ubicación, principales manifestaciones, y sus principales fuentes o causas. En tercer lugar, que a partir de las características encontradas se presentan diversas tipificaciones de estos conflictos en el país.

La estructura del trabajo, a fin de exponer los resultados de cada una de las tareas mencionadas, se divide en cuatro apartados. En el primero se desarrolla teórica y conceptualmente lo que representa un conflicto social, sus lógicas de clasificación o tipificación, y más específicamente lo que se entiende en este trabajo por conflictos subnacionales en torno al agua. En el segundo apartado se resume el estado del arte sobre el estudio de estos conflictos en México, destacando algunos esfuerzos por sistematizar información al respecto. Ya en la tercera sección se expone la metodología y se describen los datos obtenidos de su aplicación al caso mexicano. Finalmente se hacen algunos comentarios a manera de conclusión y se plantean retos a futuro que surgen del trabajo realizado.

\section{Conflictos en torno al agua}

Resulta difícil establecer una definición tajante de conflicto social; sin embargo, existe mucha literatura que ayuda a tener un mejor entendimiento y establecimiento de elementos comunes que sinteticen sus características y funciones. Atendiendo a ello, en este apartado se exponen diferentes conclusiones surgidas de la revisión de dicha literatura, ordenándolas en función de las siguientes preguntas: ¿qué es un conflicto social? ¿Qué se entiende por conflictos en torno al agua y cómo se pueden clasificar? 


\section{¿Qué es un conflicto social?}

En la búsqueda de elementos comunes para entender un conflicto social, éste ha sido estudiado desde diferentes disciplinas y enfoques teóricos, pero de acuerdo con Caballero (2009), siendo un hecho inherente de la sociedad, éstos han sido investigados principalmente desde la sociología, emergiendo diferentes corrientes o escuelas sociológicas con sus propias definiciones y métodos de estudio. En esta misma línea, Pettersson (2011) explica que el conflicto social es un concepto ambiguo que tiene varios significados en la vida cotidiana y que puede referirse a algún tipo de comportamiento o acción, pero también puede ser entendido como una noción abstracta.

A pesar de lo anterior, diversos autores concuerdan en que los conflictos sociales son situaciones en las que dos o más actores o grupos de actores tienen o creen tener incompatibilidad de intereses, ideas, objetivos, posturas, valores y/u opiniones (y las manifiestan) en torno a recursos materiales y/o inmateriales, así como a las causas y soluciones del problema que los mantiene en conflicto (Mitchell, 2005; Bar-Tal, 2000; Kriesberg, 2005; Schlager y Heikkilä, 2009; Petterson, 2011; Herz, 2011). Pero, en realidad, en este trabajo se considera que éste es un fenómeno más complejo y al menos cuatro aspectos se deben añadir a esa noción. El primero de ellos, aunque parezca obvio, es que el conflicto social tiene un contenido humano implícito, pues siempre trata de incompatibilidades, discrepancias y/o desacuerdos entre seres humanos, y pueden ser tanto individuales o intrapersonales, como grupales o interpersonales (Kriesberg, 2005; Bar-Tal, 2000; Santacruz, 2012).

El segundo aspecto es que los conflictos no son inherentemente negativos. Aunque regularmente se suele asociar este concepto como sinónimo de lucha, combate, problemas y otros términos negativos similares, la verdad es que, como señala Herz (2011), éstos pueden ser catalizadores para el 
cambio social positivo, ya que a pesar de ser una experiencia intensa en la comunicación e interacción, que además puede llegar a ser violenta, tienen potencial transformador y llegar a ser beneficiosos si se les da un tratamiento adecuado (Buckles, 1999; Vallacher, Coleman, Nowak y Bui-Wrzosinska, 2010). El tercer aspecto es que cada conflicto es único en el sentido de que son irrepetibles y específicos por su variación en grado, expresión, intensidad, duración, entre otros aspectos. Ante ello, Herz (2011) señala que aunque éstos ocurren en todas las sociedades, sin importar su origen cultural, cada sociedad puede establecer su propia cultura del conflicto, influyendo en cómo evolucionan y la forma en que es probable que terminen. El cuarto aspecto, muy asociado al tercero, es que los conflictos son dinámicos. Esto implica que cambian según el contexto (social, económico, cultural e institucional) y su desarrollo en el espacio y el tiempo.

Conflictos subnacionales en torno al agua: definición, causas y tipologías

El binomio agua-conflicto parece ser algo indisoluble e incluso inevitable, sosteniéndose en el argumento de ser un recurso vital pero escaso, lo cual lo vuelve objeto de disputa en el presente y futuro, llegándose incluso a vaticinar guerras asociadas al recurso. Sin embargo, dicha indisolubilidad no está muy clara en el debate teórico y/o empírico, existiendo en la literatura diversos argumentos tanto a favor como en contra (Yoffe et al., 2004). Por un lado, están autores que basan sus argumentos en la escasez del recurso como elemento potencial generador de problemas y conflictos (Castillo, 2008; Tomas, 2017; cNA, 2017; Hernández, 2017), ya sea por su acceso, distribución o simplemente por el control del mismo como una fuente de poder en diferentes escalas geográficas (Fernández-Jáuregui, 2001). Por otro, se señala que el agua como fuente de conflictos es extremadamente sobrevalorada ya que hay muy poca base 
empírica para apoyar dichas conclusiones, puesto que si bien ha habido eventos conflictivos en torno al agua, éstos han sido esporádicos y ha habido también eventos exclusivos de cooperación (Instituto Danés de Estudios Internacionales [IDEI], 2006; Stetter, Herschinger, Teichler y Albert, 2011).

A pesar de no haber conclusiones determinantes sobre la relación agua-conflicto, el hecho es que existen conflictos sociales relacionados con el vital recurso, incluso la Organización Mundial del Agua establece que la gestión del agua está directamente relacionada con la gestión de conflictos (Mestre, 2005). En el caso del nivel geográfico que atañe a este trabajo, diversos autores (Yoffe et al., 2004; Selby, 2005; Gleick y Heberger, 2014; Liber y Bautista, 2015) han estado haciendo hincapié en que en los últimos años se ha visto un aumento en el número total de informes de conflictos violentos por el agua, siendo los de escala local los más numerosos, implicando violencia local sobre la distribución y uso del agua, así como sobre las decisiones de desarrollo local que afecten a las condiciones ambientales y económicas.

Además, aunque estos mismos autores resaltan que muchos de estos conflictos se deben a la escasez del agua, Kreamer (2012) menciona que en conflictos y guerras regionales o locales a menudo el agua se ha utilizado más como parte de una estratagema para promover objetivos políticos, de tal manera que no siempre el agua es el objeto de disputa, sino algunas veces su causa o un simple instrumento. Debido a esto último, en este trabajo se acuña el término "en torno o relacionado", más que "por" el agua, para tener una visión más amplia en la que se reconozca y tome en cuenta la existencia tanto de conflictos directos como indirectos por el agua.

Dicho lo anterior, en general los conflictos en torno al agua se pueden englobar en la definición de conflictos socioambientales. Sin embargo, de acuerdo con Liber y 
Bautista (2015), debido a que éstos (por, relacionados o vinculados) constituyen simultáneamente un problema económico, social, político, ambiental y cultural que involucra conflictos de intereses y de poder de orden público, presentan particularidades respecto de los conflictos socioambientales, justificando desde el punto de vista epistemológico su tratamiento autónomo, aunque no puedan ser catalogados exclusivamente hídricos o por el agua.

De esa manera, los conflictos sociales en torno al agua se definen como aquella situación que se genera cuando dos o más actores sociales (individuos, organizaciones, dependencias gubernamentales, empresas, entre otros) entran en confrontación por el acceso, disponibilidad, calidad, oportunidad, uso y/o beneficio de los recursos hídricos y sus bienes asociados, y lo manifiestan a través de diversas acciones (ANAP, 2014). De esa manera, retomando la definición adoptada para un conflicto social y complementándola con estos elementos de la relación agua-conflicto, se establece que un conflicto subnacional ${ }^{2}$ en torno al agua es un conflicto social directo o indirecto por el agua, que se desarrolla en un nivel geográfico inferior al internacional, y por lo tanto no involucra disputas entre países. ${ }^{3}$

2. Se considera el término "subnacional" en vez de "regional" porque simplemente se toma en consideración la dispersión geográfica de los actores involucrados en el conflicto tomando en cuenta las delimitaciones geográficas oficialmente establecidas que se abarcan. En ese sentido, si se habla de "regional" existe ambigüedad acerca de si se trata de una región internacional (compuesta de varios países), intranacional (compuesta por varios estados), interestatal (compuesta por varios municipios de un mismo estado) e incluso intermunicipal (compuesta por comunidades de un mismo municipio). De esa manera, con el uso del término "subnacional" se engloba cualquiera de esas opciones y otras más.

3. Es importante diferenciar conflicto relacionado con el agua de problema relacionado con el agua. Los problemas en muchos casos derivan en conflictos, sobre todo cuando involucran dos o más partes, pero mientras no haya manifestaciones de desacuerdo en alguna de las partes no puede ser clasificado como conflicto. 


\section{Estudio y causas de los conflictos en torno al agua}

La resolución exitosa de conflictos en torno al agua requiere la comprensión de la naturaleza del conflicto y después el modelado y análisis de los problemas inherentes a él (Nandalal y Simonovic, 2003). En cuanto a las relaciones causa-efecto, los conflictos relacionados con el agua son separados artificialmente a partir de factores que supuestamente son independientes en su entorno social que, si bien puede ser un enfoque tecnocrático, no se traduce necesariamente en la resolución de conflictos (Stetter et al., 2011). En general, aunque la mayoría de los argumentos parecen asociar lo vital y escasez del agua como la causa misma de conflictos, es importante poner énfasis en que a menudo existen múltiples intereses contrapuestos en la gestión del agua (Wolf, Kramer, Carius y Dabelko, 2005), de tal manera que tienen que ver con los procesos de mediación política en el manejo del recurso y organización de grupos de interés, que tal vez explican más la dinámica y aristas del conflicto, que la relación volumen de agua por habitante (Vargas y Mollard, 2004), resultando necesario fortalecer el arreglo institucional para una efectiva gobernabilidad del agua, incluyendo la resolución de conflictos (Munk, 2004). De esa manera, diversos autores asocian el trasfondo del surgimiento y agudización de los conflictos sociales en torno al agua con una crisis de gobernabilidad del agua (Vargas y Mollard, 2004; Huamani, 2006; Monforte y Cantú, 2009; Liber y Bautista, 2015).

En la literatura, aparte de aspectos intrínsecos a los actores involucrados, se identifican dos principales vertientes o visiones de causas y/o fuentes de conflictos en torno al agua: directas e indirectas. Las causas directas obedecen a situaciones de escasez o de factores que aumentan la demanda de agua, en otras palabras, por su uso y acceso (De Alba, 2007; Castillo, 2008; Monforte y Cantú, 2009; Mollard, Vargas y Wester, 2010; World Wildlife Fund [wwF], 2012; Rodríguez, 
2013; Autoridad Nacional del Agua de Perú [ANAP], 2014; Gleick y Heberger, 2014), y las indirectas a situaciones de gestión del agua, argumentando que los conflictos se deben a la forma en que se gestiona el agua y su uso, implicando desde decisiones gubernamentales hasta el marco institucional formal y/o informal de gestión del recurso, involucrando en muchos sentidos decisiones políticas (Selby, 2005; De Alba, 2007; wWF, 2012; ANAP, 2014; Pacheco-Vega, 2014; Liber y Bautista, 2015) (véase cuadro 1).

\section{Cuadro 1. Causas y/o factores relacionados} con los conflictos en torno al agua

\begin{tabular}{|c|c|}
\hline Directas & Indirectas \\
\hline $\begin{array}{ll}\text { - } & \text { Desarrollo industrial y } \\
\text { agrícola } \\
\text { Incrementos } \\
\text { poblacionales } \\
\text { - Urbanización y } \\
\text { modernización } \\
\text { - Globalización } \\
\text { económica } \\
\text { Contaminación de } \\
\text { fuentes } \\
\text { Degradación del medio } \\
\text { ambiente } \\
\text { - Sequías } \\
\text { - Situación geográfica } \\
\text { Insuficiencia para } \\
\text { diferentes usos } \\
\text { Cambio climático }\end{array}$ & $\begin{array}{ll}\text { - } & \text { Obras hídricas } \\
\text { - } & \text { Decisiones políticas para su } \\
\text { - } & \text { Admintribución } \\
\text { - } & \text { Afectación de derechos de } \\
\text { comunidades } \\
\text { - } \\
\text { Definición de derechos de } \\
\text { - } \quad \text { Debopiedad } \\
\text { - No inclusión en toma de decisiones } \\
\text { - Corrupción } \\
\text { - Deficiencia y/o ausencia de } \\
\text { información } \\
\text { Cosmovisiones distintas en torno } \\
\text { al agua } \\
\text { - Ausencia de protocolos de atención } \\
\text { a conflictos } \\
\text { Pobreza } \\
\text { Hidropolítica }\end{array}$ \\
\hline
\end{tabular}

Fuente: elaboración propia con base en revisión de literatura.

4. De acuerdo con Caldera (20I2), las ideas, valores y creencias en torno al agua giran en torno a dos principales visiones contrapuestas: el agua como bien económico o como derecho humano. De tal manera que los procesos políticos en torno al agua (a cualquier escala geográfica) se enmarcan en disputas por hacer prevalecer una determinada visión. 
Teniendo en cuenta esas visiones, se puede decir que tanto factores intrínsecos como extrínsecos pueden provocar conflictos en torno al agua y de igual manera el curso que tomen una vez que aparecen. Pero se debe aclarar que éstos no son mutuamente excluyentes, incluso lo más usual es una mezcla de ellas, ya que rara vez un conflicto en torno al agua es exclusivo de un factor o causa, ya que como señala la Agencia de Estados Unidos para el Desarrollo Internacional (USAID, 2014), estos conflictos emergen en diferentes escalas geográficas, pero es la interacción de una serie de factores políticos, socioeconómicos, ambientales y culturales la que determina si el conflicto resulta violento. En este sentido, Santacruz (2012) afirma que es necesario tener en cuenta que no sólo por la escasez, sino también ante la distribución injusta de recursos, surgen conflictos sociales.

\section{Tipologías de conflictos en torno al agua}

Como se señaló en apartados previos, los conflictos en torno al agua difícilmente se pueden categorizar exclusivamente de una manera; sin embargo, diversos autores han establecido algunas tipologías específicas que en el siguiente cuadro se resumen. Destaca la de Berg (2007), quien obedeciendo a la lógica de la fuente de los conflictos en torno al agua y para contribuir en el diseño e implementación de políticas, propone lo siguiente: a) conflictos cognitivos (basado en los desacuerdos técnicos respecto a cómo deberían ser analizados e interpretados los datos); b) de intereses (donde proveedores y demandantes obtienen diferentes beneficios y costos bajo políticas alternativas); c) de valores (que implica preferencias ideológicas o personales respecto a los resultados del sector agua), y d) de autoridad (derivados de discrepancias jurisdiccionales sobre quién tiene la última palabra). 
Cuadro 2. Tipologías de conflictos relacionados

con el agua establecidas por diversos autores

\begin{tabular}{ll}
\hline \multicolumn{1}{c}{ Autor(es) } & \multicolumn{1}{c}{ Categorías o tipologías } \\
\hline Haftendorn (2000) & Por el uso \\
& Por la contaminación \\
& Por la distribución \\
\hline Schlager y Heikkilä & Por cuestiones de distribución \\
& Por cuestiones de aguas arriba y aguas abajo \\
& Por problemas de compatibilidad entre las \\
& leyes y pactos estatales \\
\hline Berg (2007) & Conflictos cognitivos \\
& De intereses \\
& De valores \\
& De autoridad \\
\hline De Alba (2007) & Conflictos sociopolíticos \\
& Conflictos socioinstitucionales \\
\hline Ohlson (2000) Munk & Conflictos de primer orden (directos) \\
(2004) & Conflictos de segundo orden (indirectos) \\
\hline Liber y Bautista & Conflictos entre usos \\
(2015) & Entre usuarios \\
& Con actores no usuarios \\
& Intergeneracionales \\
& Interjurisdiccionales \\
& Institucionales \\
\hline ANAP (2014) & Temáticos (por cantidad, calidad, \\
& oportunidad, entre otros) \\
& Por etapa (prevención, tratamiento o \\
& monitoreo) \\
\hline
\end{tabular}

Fuente: elaboración propia con base en la revisión de literatura.

De igual manera destaca la tipología establecida por Liber y Bautista (2015), que optan por una tipología más amplia al hablar de: 1) conflictos entre usos, que ocurren cuando no se satisface la necesidad de uso en diferentes actividades; 2) entre usuarios, que se centran en las características de los actores involucrados; 3) con actores no usuarios, cuando no son directamente por competencia por el recurso sino por acciones de terceros vinculadas al uso del agua; 4) 
intergeneracionales, relacionados con el cuidado de los recursos hídricos para generaciones presentes y futuras; 5) interjurisdiccionales, que se centran en las tensiones entre los objetivos y competencias de diferentes divisiones político-administrativas, y 6) institucionales, que ponen de manifiesto las disputas entre los diferentes actores públicos y privados cuyos ámbitos de actuación impactan en la gestión y el aprovechamiento del agua.

Hay otros ejemplos, ${ }^{5}$ sin embargo, debido a que tanto el conflicto en torno al agua como el conflicto social son multidimensionales, dinámicos e irrepetibles en toda su esencia, cada investigación o estudioso de los conflictos del agua puede establecer su propia tipología según lógicas diferentes. Aún más, un mismo conflicto puede ser clasificado en diferentes tipos. Por ejemplo, en general los conflictos en torno al agua se definen como socioambientales, pero aunque la presencia de los problemas ambientales es evidente, éstos implican más allá de eso (Musseta, 2010).

\section{El estudio de los conflictos en torno al agua en México}

Como ya se mencionó, en México tanto desde la academia como por las autoridades, incluso en la prensa, ${ }^{6}$ se ha hecho y está haciendo hincapié en el creciente número de conflictos en torno al agua, así como en su creciente alcance y severidad. Algunos autores señalan el agravamiento de los problemas de escasez en las últimas décadas (debido entre otras causas a la expansión urbana e industrial, lo cual ha reducido la seguridad hídrica del país) como el principal factor del incremento de la tensión en la competencia por el recurso, no sólo al interior, sino con otros países, y

5. El Instituto Mexicano de Tecnologías del Agua (IMTA, 20I5) presenta otros tantos en su Boletín núm. 2, que se puede consultar en el siguiente link: http://ocam.imta. $\mathrm{mx} /$ data/boletines/2.pdf

6. La Jornada, 20I5; Reforma, 2015. 
prevén un escenario de mayor conflicto y complejidad en las relaciones agua-sociedad-medio ambiente en México (Ávila, 2002; Jiménez y Torregrosa, 2007; Becerra, Sainz y Muñoz, 2006; Rodríguez, 2012).

Por otro lado, hay quienes señalan que parte de la política hídrica es la causante de muchos de los conflictos en torno al agua. Ya que, por una parte, han favorecido al sector privado y se han enfocado primordialmente en el diseño de mecanismos preponderantes para incrementar la oferta de agua potable, lo cual ha elevado la competencia por el acceso al agua y la oposición a dichas políticas (Becerra, Sainz y Muñoz, 2006; Perevochtchikova, 2010; Toledo, Garrido y Barrera-Bassols, 2014). Muy relacionada con la anterior, una tercera vertiente hace referencia a aspectos asociados al arreglo institucional en torno a la gestión del agua en el país. Vargas y Mollard (2004) señalan que los conflictos por el agua se han generalizado debido a una "crisis de gobernanza del agua en México" caracterizada, entre otras cosas por insuficiencias en el arreglo institucional, falta de gobernabilidad, así como un rápido proceso de politización, conformación de grupos de interés y movimientos sociales, en un contexto de creciente presión por el agua, lo cual torna más difícil consensuar posturas antagónicas (Mollard, 2007; Mollard, Vargas y Wester, 2010).

Ante esto, Amaya (2007) sostiene que cumple un papel importante la falta de corresponsabilidad (gobierno-sociedad), específicamente en lo que respecta a que la vigilancia de actores para el cumplimiento y logro de objetivos, al no haber una vigilancia mutua, sólo del Estado hacia los ciudadanos, lo cual disminuye la capacidad de sancionar a infractores, a aquellos que no cooperen y no acaten las reglas que el diseño institucional establece. De tal manera que el estudio profundo desde la perspectiva institucional permitiría ser más precisos en la identificación de las características que los arreglos institucionales presentan,

\section{2}


aportando elementos de rediseño institucional para una mejor gestión de este recurso vital y evitar el agravamiento de los conflictos sociales en torno al agua (Amaya, 2007).

Existe consenso en que los conflictos en torno al agua representan un problema público que debe ser atendido en México, pero a pesar del panorama y de argumentos planteados por los autores citados anteriormente, una constante sobre conflictos en torno al agua en el país es la ausencia u opacidad de datos sobre los mismos, así como la falta de estudios sistemáticos para la caracterización y comprensión de las causas que generan y agravan estos conflictos. Incluso, desde las políticas públicas, Ruiz (2016) considera que existe una negación de agenda gubernamental en torno a la atención al problema de conflictos en torno al agua, lo cual significa que a pesar de que en el discurso oficial se reconoce el problema e incluso se acepta que es prioritario atenderlo, en el papel, y sobre todo en la práctica existen vacíos y ausencias para ello, caracterizándose lo existente como el establecimiento de mecanismos o acciones simbólicas sin los elementos necesarios (sistemas de monitoreo, protocolos de actuación ante conflictos, estructuras organizativas, entre otros) para su prevención, resolución y/o tratamiento efectivo.

\section{Información y datos sistemáticos sobre}

\section{conflictos en torno al agua en México}

En cuanto al tema de este trabajo, a diferencia de países como Perú y Chile, en México aún no se cuenta con un sistema gubernamental de identificación y seguimiento de conflictos relacionados con el agua. La mayor parte de las estadísticas que existen al respecto se han compilado de fuentes periodísticas y algunas fuentes oficiales que presentan datos esporádicos sobre alguna situación conflictiva en torno al agua. Sin embargo, a pesar de la imperfección de dichas fuentes (sesgo en la información, no representa- 
tividad nacional, falta de rigurosidad metodológica, entre otras), diversos autores e instituciones han hecho esfuerzos por sistematizar estadísticas referentes a dicho fenómeno social a partir de ellas. Destaca el caso de Becerra, Sainz y Muñoz (2006), quienes revisaron más de 5,000 notas de tres de los principales periódicos de circulación nacional y contabilizaron alrededor de 200 conflictos relacionados con el agua para el periodo 1990-2002.

También destaca el caso del Observatorio de Conflictos por el Agua, plataforma virtual (aún en construcción) operada por el IMTA, que a partir de la ubicación y sistematización de notas periodísticas de cuatro diarios de circulación nacional y otros medios on line ofrecen información sobre problemáticas y conflictos relacionados con el agua, llegando a acumular desde 2007 más de 7,000 notas periodísticas relacionadas con problemáticas y conflictos en torno al agua y que pueden ser consultadas en su página de Internet (http://ocam.imta.mx/inicio.html), donde se presenta la ficha descriptiva de siete conflictos que actualmente se desarrollan en el país. Otro caso es el de Toledo, Garrido y Barrera-Basols (2014), quienes en su estudio mencionan que en el tema de los conflictos hidráulicos hay 12 estados con este tipo de afectaciones (33 conflictos), destacando los debidos a proyectos de construcción de acueductos y presas, contaminación de cuerpos de agua, sobreexplotación de mantos acuíferos y la mala distribución del líquido vital, involucrando a entidades privadas, organizaciones no gubernamentales, así como diversas instancias gubernamentales.

Dichos casos presentan diferentes limitaciones que en este trabajo se busca avanzar en ellas; por ejemplo, en algunos no queda clara la diferenciación entre problemáticas y conflictos en torno al agua, confundiéndose en su contabilidad; la cobertura de los diarios utilizados como fuente deja de lado conflictos que no han logrado tener presencia 
en prensa nacional, sino sólo a nivel local o regional; y no existe consenso en cuanto a las tipologías consideradas. Además, en este trabajo se da un giro a la identificación y caracterización de los conflictos, cambiando del enfoque de contabilidad y análisis de noticias relacionadas con conflictos en torno al agua, al enfoque de conflicto, consistente en la identificación de casos de conflictos y su posterior profundización con búsqueda de información sobre él, tanto en fuentes hemerográficas como en otro tipo de documentos, como es el caso de artículos académicos, si los hay.

\section{Panorama de los conflictos en torno al agua en México}

En este apartado se detalla la metodología-protocolo seguido para la identificación de los conflictos y se exponen los resultados obtenidos.

\section{Metodología: fuentes de información}

\section{y protocolo de recolección de datos}

Teniendo en mente la definición de conflictos subnacionales relacionados con el agua, se procedió a su identificación vía Internet haciendo búsqueda en diarios on line, en blogs, artículos académicos y otros espacios de comunicación disponibles en Internet, usando el buscador de Google, bajo los parámetros de búsqueda (en diferentes órdenes y combinaciones): conflicto, disputa, agua, nombre del estado en turno y en algunos casos de municipios importantes del estado, entre otros términos similares. Los resultados con títulos de interés se agruparon en carpetas correspondientes a cada estado de la República y posteriormente se analizó su contenido para determinar qué situaciones realmente se podrían conceptualizar como un conflicto en torno al agua; para ello el criterio fue identificar que hubiera partes en desacuerdo sobre acciones relacionadas con el agua (ya sea por su acceso, distribución, calidad y/o gestión). Además, 
que dicho conflicto se encontrara activo al momento de su identificación, lo que se determinó a partir de la actualidad de la información (no más de seis meses) y/o que en ella no se especificara la ya solución del mismo (en la figura 1 se esquematiza el proceso de toma de decisión completo).

Una vez pasados los dos filtros anteriores, se realizó una búsqueda profunda enfocada en cada caso, a fin de identificar diversas características previamente definidas, como son la fecha aproximada de emergencia del conflicto, principales reclamos presentes en el conflicto, su ubicación exacta, las formas de manifestación presentes, los principales actores involucrados, entre otras. En un primer momento se contemplaron respuestas tal y como se encontraban en el contenido de los documentos analizados, pero después se hizo una depuración de datos en función de las categorías o etiquetas de mayor incidencia, de tal manera que las clasificaciones expuestas se derivan de los resultados obtenidos. 
Figura 1. Representación del proceso metodológico

Wpara la concentración de datos

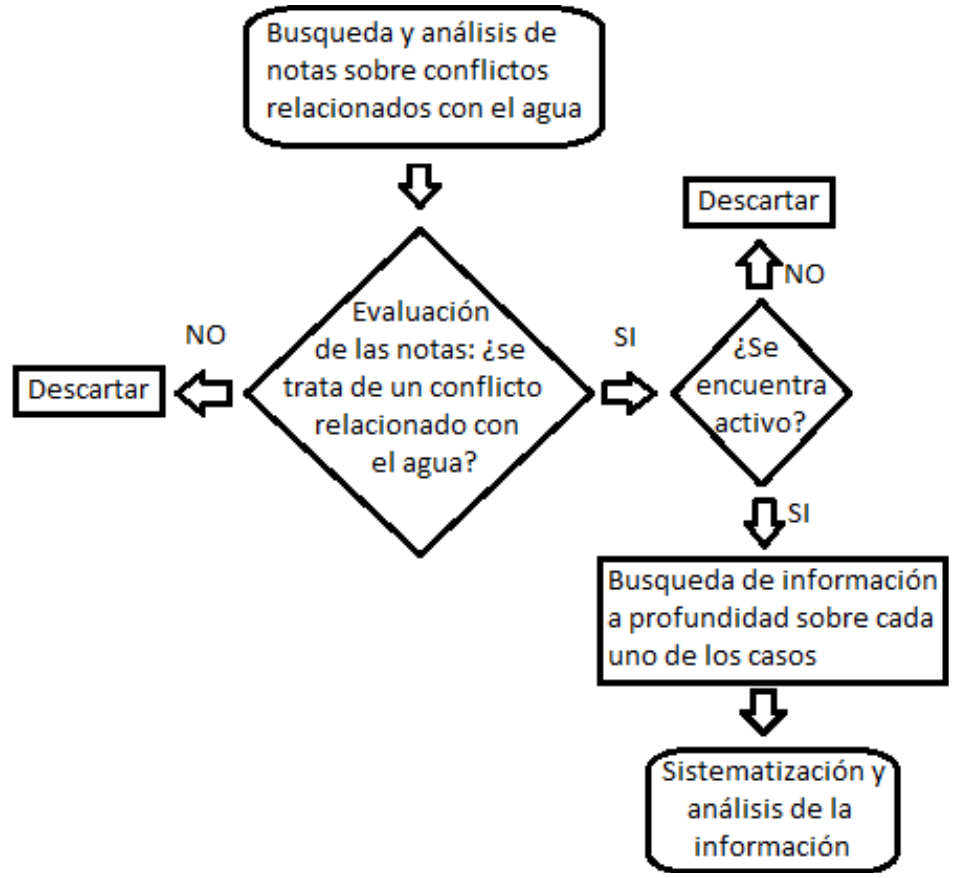

Fuente: elaboración propia.

Antes de pasar a los resultados es importante reconocer diversas limitaciones que enfrenta esta metodología. En primer término, aun y considerando fuentes de datos a nivel local, es difícil asegurar una cobertura de 100\% de los casos que existen en el país, puesto que existen conflictos que por diversos motivos no alcanzan a mediatizarse. En segundo término, aunque se describan detalladamente los pasos y criterios, debo reconocer que siempre habrá un componente subjetivo en la identificación y "cuantificación de categorías". 
Resultados de características de los conflictos

En este apartado sólo se exponen resúmenes estadísticos de las variables encontradas a partir de la revisión hemerográfica y que son de carácter más bien descriptivo, como es el caso de la distribución geográfica de los conflictos, principales manifestaciones, entre otras.

\section{Distribución geográfica}

En total se identificaron 89 conflictos relacionados con el agua en el país, los cuales están distribuidos en 27 estados de México (véase figura 2). Puebla es el estado donde más conflictos se detectaron (10), seguido de Jalisco (siete) y el Estado de México (siete), Veracruz (seis), Chiapas (cinco) y Baja California (cinco) y Coahuila, Hidalgo y Oaxaca con cuatro cada uno.

Gráfica 1. Conflictos activos en torno al agua por región en México

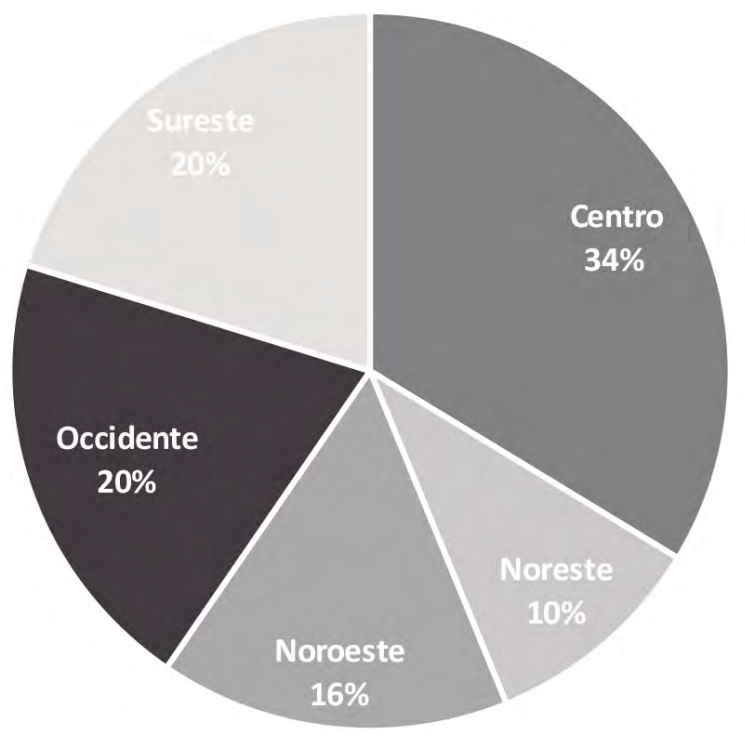

Fuente: elaboración propia con base en la metodología aplicada. 
Visto por región, en la gráfica 1 se puede observar que la mayor parte se ubican en la región centro del país (que contempla al Estado de México, Distrito Federal y Morelos), pues 34\% (30) se ubican ahí. No se cuenta con información precisa para elaborar conclusiones y/o conjeturas atinadas sobre el porqué de esta concentración, pero un argumento guiado por la intuición a partir del conocimiento sobre datos oficiales de disponibilidad de agua en esta región y sus datos poblacionales, consiste en que esta concentración se podría deber a que es una de las regiones con menor disponibilidad per cápita anual del recurso. ${ }^{7} \mathrm{~A}$ lo cual se agrega una mayor densidad poblacional con las problemáticas administrativas que ello conlleva para dotar a la población con un recurso de buena calidad y en cantidad suficiente.

Figura 2. Distribución por estado de conflictos en torno al agua en México

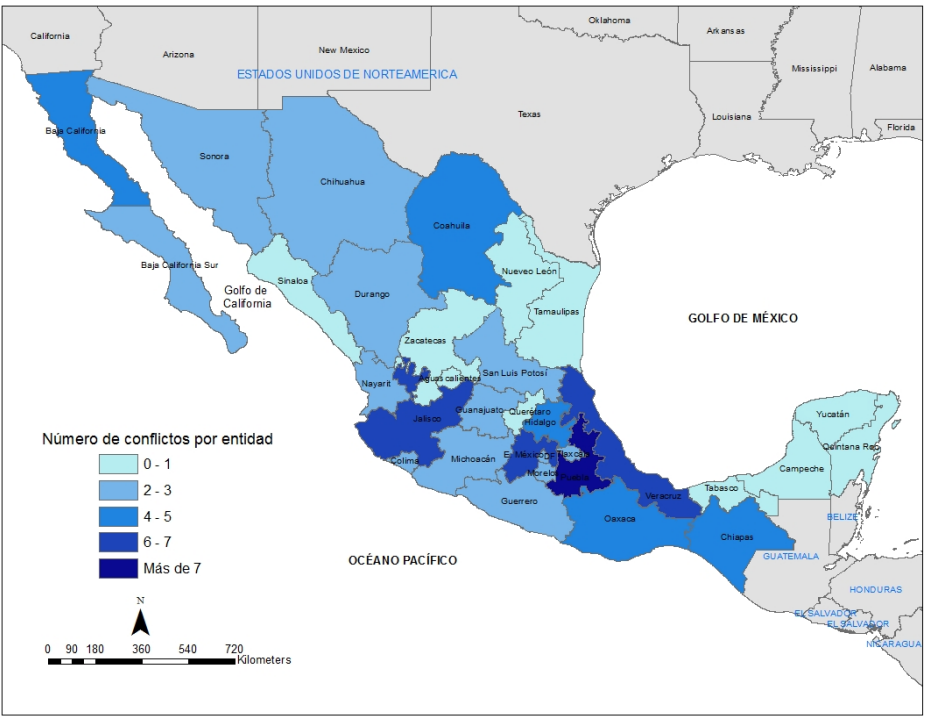

Fuente: elaboración propia con base en la metodología aplicada.

7. Comisión Nacional del Agua. (2014). Atlas del agua en México. México:Secretaría de Medio Ambiente y Recursos Naturales. 


\section{Alcance geográfico}

Otra característica interesante de los conflictos es su alcance geográfico, el cual se refiere a la dispersión de los actores involucrados directamente en el conflicto. En la gráfica 2 se presentan los porcentajes de conflictos que se ubicaron en cada una de las cuatro categorías consideradas. En términos generales, en dicha gráfica se puede observar que el mayor porcentaje de conflictos presentan un alcance geográfico municipal - con actores en dos o más comunidades pero dentro de un mismo municipio- (36\%); o regional (o intermunicipal) ${ }^{8}$ —actores en comunidades de dos o más municipios, pero dentro de un mismo estado- (35\%), y en menor medida son de alcance local - actores ubicados en una sola comunidad - o interestatal - actores ubicados en dos o más comunidades y/o municipios de dos o más estados- (19 y 10\% respectivamente). Se puede concluir que, en el caso de México, como mencionan algunos autores (Selby, 2005; Gleick y Heberger, 2014; Liber y Bautista, 2015), además de que los conflictos subnacionales son numerosos, su alcance geográfico dentro del país no tiende a extenderse demasiado, sino más bien tienen alcance geográfico medio.

8. La definición de lo regional es realmente ambigua, pudiéndose tomar diversos elementos determinantes de una para hablar de "región"; por ejemplo, una región económica definida por el tipo de producción dominante, sin importar las delimitaciones geográficas. En este caso, simplemente se toma en consideración al alcance en cuanto a las delimitaciones geográficas oficialmente establecidas que se abarcan, $y$ aun así sigue habiendo ambigüedad porque se puede hacer referencia, entre otras, a una región internacional, compuesta de varios países, o a una región intranacional, compuesta por varios estados. Para efectos de este trabajo se estaría hablando de una región interestatal que abarca dos o más municipios.

\section{0}


Gráfica 2. Alcance geográfico de los conflictos

en torno al agua en México

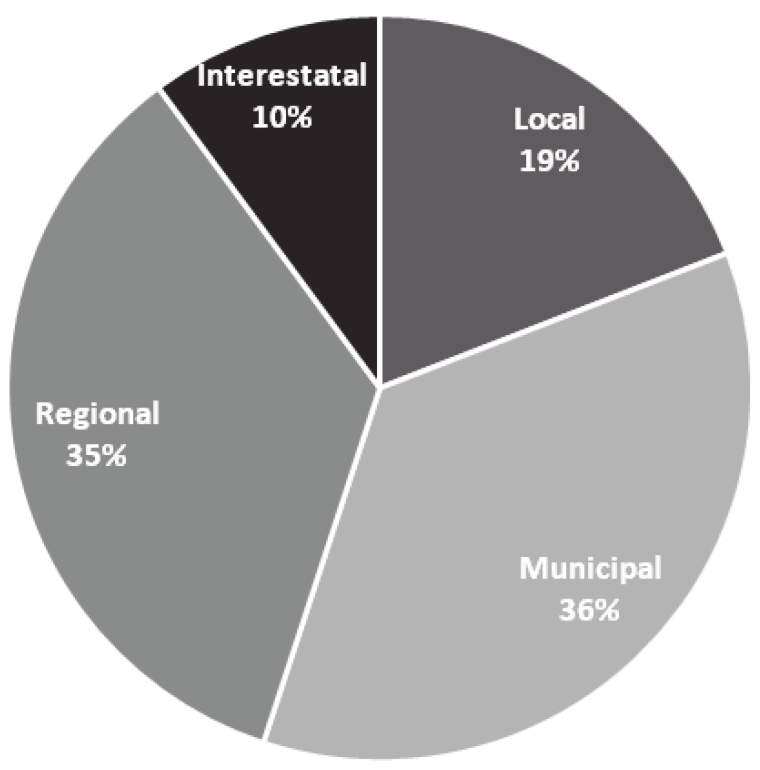

Fuente: elaboración propia con base en la metodología aplicada.

Sin embargo, dicha conclusión, al menos en los datos a nivel local, tiene sus limitantes debido a que uno de los argumentos que se dan en la literatura sobre factores que influyen en la mediatización de conflictos, es que cuando éstos se quedan a nivel comunitario es más difícil que se vuelvan visibles para la prensa, por un lado porque los actores en esos niveles tienen poca capacidad de movilización y argumentación de demandas, o simplemente porque son zonas de difícil acceso geográfico en las que a veces el único medio de comunicación es la radio, y en los casos en los que otros medios como la prensa o televisión sí dan visibilidad a los conflictos, éstos se centran en los conflictos con las autoridades y hay menos cobertura para los conflictos socioambientales (Macassi y Subauste 2009). De tal manera 
que ese número bajo de conflictos relacionados con el agua identificados en este trabajo, se deba a que no recibieron cobertura, al menos por los medios considerados aquí.

\section{Fuentes o causas de conflictos}

Los conflictos rara vez tienen una única fuente o causa, regularmente son una combinación de ellas y otros factores. Sin embargo, para este trabajo se hizo una clasificación que atendió a cuáles eran los reclamos principales que hacían las partes o actores identificados como involucrados en conflicto, usando como criterio de "principalidad" el reclamo que más presencia tenía en el discurso de dichos actores (mayor número de alusiones y/o alusiones directas a dicha causa). Las temáticas mencionadas a nivel de detalle fueron múltiples; sin embargo, fue posible englobarlas en cinco grandes categorías: contaminación de fuentes de agua, escasez de agua, deficiencias en administración del agua, obras hídricas y privatizaciones.

La primera categoría hace alusión a conflictos en los que el principal reclamo está relacionado con la contaminación de alguna fuente de agua o con la posible contaminación de agua que generan o generará algún proyecto o acciones de determinados actores públicos o privados. Por ejemplo, cuando hay grupos demandando el cuidado de determinadas fuentes de agua, el alto a su contaminación por diversos medios (industrial, minera, doméstica, entre otras) y/o la restitución de daños relacionados con contaminación de fuentes acuíferas. Aquí, un ejemplo específico es que en algunos casos existe un conflicto en torno a la construcción de una planta tratadora de aguas negras, donde el principal reclamo es evitar (que se tomen las medidas necesarias para ello) la contaminación que se va a generar, porque si el reclamo es evitar la construcción de la planta en algún punto en específico o en su totalidad, su categorización sería otra (por obra hídrica). 
La segunda categoría considera las disputas que son directamente por el recurso hídrico debido a su escasez para cubrir la demanda de cierto grupo o grupos y/o de actividades económicas y/o sociales de manera simultánea. Pueden ser disputas entre usuarios cuando el agua disponible no alcanza para ambos, también por la disputa para su uso prioritario en algún sector, por ejemplo uso doméstico contra uso industrial y/o agrícola, así como por el corte de suministro. Ejemplo de esta situación es cuando alguna comunidad demanda escasez de agua por sobreexplotación de mantos acuíferos a partir de actividades mineras, pero si el reclamo más que sobreexplotación es la contaminación que genera la minería o la que se espera que genere, el conflicto se catalogará en la primera categoría: contaminación.

La tercera categoría hace referencia a conflictos desatados por deficiencias en la administración del recurso, lo cual se entiende como conflictos desatados por algún descontento u oposición hacia quienes están administrando, hacia la forma en que están administrando, y/o hacia los resultados de su administración (deficiente servicio, por ejemplo). Aquí un ejemplo contrastante es el conflicto que surge ante una obra hídrica, donde el principal reclamo no es evitar la construcción, sino a la forma en que se distribuirá o el uso que se le dará al agua que se almacene. De igual manera, se pueden considerar aquí los conflictos por la distribución del recurso en distritos de riego agrícola.

La cuarta categoría se refiere a conflictos desatados por o a partir de la oposición a la construcción de alguna obra hídrica o de infraestructura hidráulica en general (evitar las presas, hidroeléctricas, acueductos, plantas tratadoras, desaladoras, entre otras obras). Éstos pueden ser por la oposición al proceso de planeación, construcción y/u operación de la obra; por la oposición a los daños sociales, económicos y/o ambientales que implicará la obra; por desacuerdos en las indemnizaciones de personas desplazadas; por pro- 
blemas de índole limítrofe y/o territorial entre diferentes demarcaciones geográfico-administrativas o particulares; entre otras cuestiones. Un ejemplo de este caso es el de la construcción de una planta tratadora de aguas negras, donde el principal reclamo es evitar que se ubique en determinado espacio o de plano en ningún espacio.

Finalmente, la quinta categoría considera conflictos que tienen como trasfondo la privatización de fuentes del recurso y/o la administración del mismo. En general se puede ubicar aquí a conflictos en los que el principal reclamo y preocupación de los demandantes va encaminado a evitar o regular la participación de privados en la administración y/o aprovechamiento del agua como recurso público. Aquí se citan casos como el de oposición a concesiones de sistemas de administración y proveeduría de agua potable en diversos municipios del país, así como concesiones a empresas privadas para el embotellamiento de agua o minería.

Antes de presentar los resultados es importante recalcar lo difícil que resultó ubicar los casos en una sola categoría, de tal manera se debe reconocer que alguno de ellos bien podría haberse categorizado en otra opción. Considerando las categorías establecidas, se encontró que la mayor parte de los conflictos en México tienen como trasfondo una mala administración (37.1\%), seguidos por los detonados por o a partir de obras hídricas (23.6\%), escasez (22.5\%) y contaminación (14.6\%), y la menor incidencia fue la privatización, en cuyo caso sólo se identificaron dos disputas (véase cuadro 3). En el cuadro 3 también se enlistan algunos ejemplos que se tipifican en las categorías consideradas.

Entre los conflictos identificados como de deficiencias en la administración se destaca el conflicto de Coyotepec, municipio que se ubica en el Estado de México y que se desató en 2013 por diversos intentos de "municipalización" del servicio de agua potable en el municipio, ya que desde principios de la década de los sesenta dicho servicio se ha 
estado administrando en la modalidad de "usos y costumbres". Casos similares son los de San Buenaventura y Ecatepec, ambos también en el Estado de México. Este último es más bien una disputa entre dos grupos políticos por hacerse del control de la administración de agua potable y alcantarillado, situación que está afectando el abasto a los usuarios. Finalmente, se enlista un caso en Villahermosa, Tabasco, donde la situación conflictiva se debe a que un grupo de colonos demandan mejor servicio de agua potable al Ayuntamiento.

Cuadro 3. Principales fuentes o causas de conflictos en torno al agua en México

\begin{tabular}{|c|c|c|c|}
\hline Fuente o causa & $\begin{array}{c}\text { Número de } \\
\text { conflictos }\end{array}$ & $\%$ & Ejemplos de casos* \\
\hline $\begin{array}{c}\text { Deficiencias } \\
\text { en la } \\
\text { administración }\end{array}$ & 33 & 37.1 & $\begin{array}{c}\text { Coyotepec } \\
\text { San Buenaventura } \\
\text { Colonia Gaviotas } \\
\text { Ecatepec }\end{array}$ \\
\hline Obra hídrica & 21 & 23.6 & $\begin{array}{l}\text { El Zapotillo } \\
\text { Acueducto Independencia } \\
\text { Desaladura La Lagunilla } \\
\text { Hidroeléctrica Las Cruces }\end{array}$ \\
\hline Escasez & 20 & 22.5 & $\begin{array}{c}\text { Minera El Peñasquito } \\
\text { Iztapalapa } \\
\text { Agricultura en Torreón } \\
\text { Desabasto en Ensenada }\end{array}$ \\
\hline Contaminación & 13 & 14.6 & $\begin{array}{c}\text { Lago Cajititlán } \\
\text { Minera Great Partner } \\
\text { Derrame en el Río Sonora }\end{array}$ \\
\hline Privatización & 2 & 2.2 & Tuxtla Gutiérrez \\
\hline
\end{tabular}

En cuanto a conflictos por obras hídricas, existen casos que son más conocidos a nivel nacional. Por ejemplo, se puede 
nombrar a la presa El Zapotillo, conflicto activo desde hace más de 10 años y que se debe principalmente a la oposición de tres localidades jaliscienses a ser inundadas por el vaso de la presa, o también el caso del Acueducto Independencia, conflicto que involucra a comunidades de la sociedad yaqui en el estado de Sonora, quienes se muestran en franca oposición al acueducto que pretende llevar agua a Hermosillo. De igual manera, se enlista el caso de la Desaladora Lagunilla, proyecto que se pretende concretar en Ensenada, Baja California, para abastecer de agua potable a parte de la población del municipio; sin embargo, diferentes habitantes y organizaciones no gubernamentales de corte ambientalista se oponen al proyecto. Y, por último, el conflicto por la hidroeléctrica Las Cruces se desarrolla en dos municipios de Nayarit y en el cual diferentes grupos de habitantes pertenecientes a etnias del estado se oponen a la inundación de localidades y sitios que ellos consideran sagrados.

Entre los conflictos enmarcados en la categoría de escasez, aparecen como ejemplo dos que se deben primordialmente a desabasto de agua potable en zonas, debido a lo cual grupos de colonos y diversos usuarios han estado haciendo protestas constantes en las que demandan al gobierno que solucione dichas situaciones, tales casos se ubican en Iztapalapa en la Ciudad de México y Ensenada en Baja California. Otros dos casos enlistados son el de El Peñasquito y el de la agricultura en Torreón. El primero se ubica principalmente en la comunidad de Cedros, perteneciente al municipio de Mazapil, Zacatecas. El móvil principal es que algunos habitantes e integrantes del Comisariado Ejidal de la comunidad demandan que la empresa minera establecida en parte de su territorio (Minera El Peñasquito, perteneciente al corporativo canadiense Gold Coorp) les enmiende el daño que ha causado y sigue causando a sus mantos acuíferos por la sobreexplotación que está haciendo de ellos. El otro caso se refiere a diversas demandas que usuarios agrícolas de la

\section{6}


comarca lagunera han estado realizando a las autoridades hídricas por las paulatinas reducciones de agua destinada a usos agrícolas, lo cual los ha estado llevando a que cada año se siembren menos hectáreas.

En la categoría de contaminación, el primer caso es el del derrame de la Minera México en el cauce del Río Sonora en el estado homónimo, y el segundo caso se desarrolla en una demarcación de la ciudad de Guanajuato, capital del mismo estado, donde se demanda que la empresa llamada Minera Great Partner está derramando desechos que están contaminando sus mantos acuíferos. El tercer caso mencionado es el del Lago Cajititlán en el municipio de Tlajomulco de Zúñiga en Jalisco, donde diversos habitantes ribereños agrupados en ONG están demandando que se reduzca o se mejore el desalojo de agua negras o tratadas provenientes de la zona metropolitana de Guadalajara, ya que en fechas recientes se ha presentado mortandad de peces. Finalmente, en el rubro de privatización sólo se encontraron dos casos y el más emblemático es el que se lleva a cabo en Tuxtla Gutiérrez, Chiapas, en el cual diversos grupos políticos y algunas ONG se oponen a que el Ayuntamiento concesione el servicio de agua potable y alcantarillado a empresas privadas.

\section{Actores involucrados: número y tipo}

En este apartado se expone el número aproximado de actores involucrados directamente en los conflictos identificados y en general el origen, demarcación o giro de los mismos. Por un lado, no se describen ampliamente porque el tipo de actores identificados van desde ciudadanos comunes, hasta dependencias federales. Sólo por ejemplificar, entre los actores más recurrentes se encontró a la Conagua, Comisiones Estatales del Agua, Organismos de Cuenca, Semarnat y otras dependencias afines a nivel estatal, gobiernos municipales y algunas de sus dependencias, organizaciones no gubernamentales en pro de la defensa del 
medio ambiente, territorio y recursos naturales, así como colectivos jurídicos y algunos representantes de la Iglesia católica, Comisariados Ejidales, Usuarios de Distrito de Riego, líderes de colonos o habitantes, productores agrícolas y comunidades indígenas.

Por otro lado, se dice "aproximado" porque es difícil que a partir de revisión hemerográfica se detecten todos los involucrados, para lo cual más bien se requiere un arduo trabajo de campo. Sin embargo, con la información recolectada se puede decir que aproximadamente en 64 casos (72\%) algún nivel de gobierno a través de alguna de sus dependencias o directamente por su representante ejecutivo está involucrado en los conflictos identificados. Y lo que es aún más notable y preocupante es que en casi el 100\% de ellos es la parte "demandada" del conflicto, dando la idea de que es necesario que se revisen los procedimientos y formas de actuación del Gobierno en torno a asuntos relacionados con el agua.

Gráfica 3. Número aproximado de actores involucrados directamente en conflictos en torno al agua en México

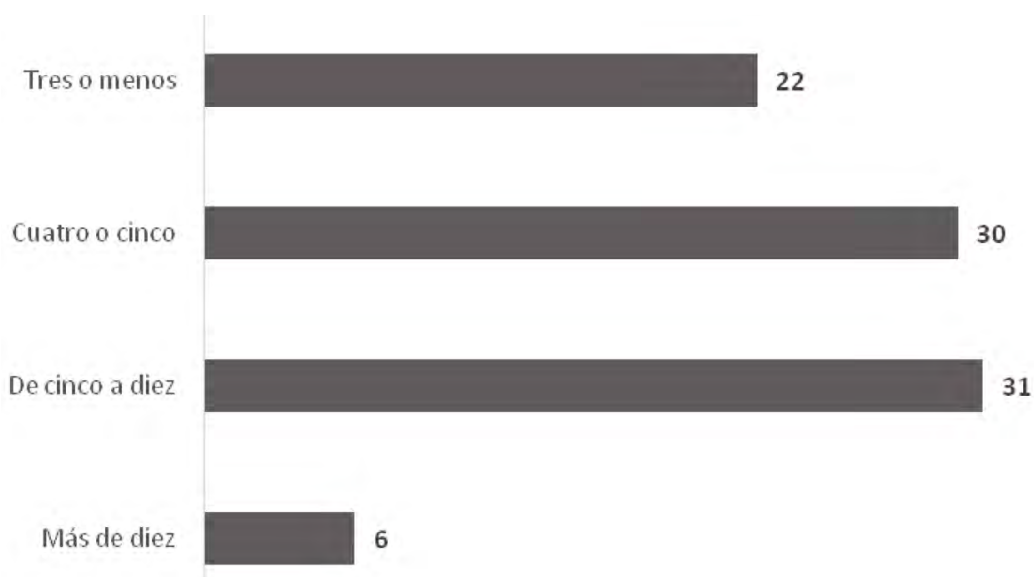

Fuente: elaboración propia con base en la metodología aplicada. 
Dicho lo anterior, en la gráfica 3 se puede notar que más de la mitad de los casos (52 de 89) identificados involucra cinco o menos actores, lo cual da la idea de que son conflictos aun no muy complejos porque las negociaciones son entre menos actores, aunque para asegurar eso es necesario conocer las características de éstos y los temas en disputa, entre otros factores. Pero el siguiente porcentaje importante es que un tercio de los conflictos ya involucran hasta 10 actores, indicando conflictos que en el papel parecen estar más politizados y por lo tanto se esperaría mayor entrampamiento de negociaciones y aspectos similares. Finalmente, son sólo seis casos en los que se identificaron más de 10 actores en la disputa.

\section{Formas de manifestación y/o acciones llevadas a cabo}

Las formas y acciones en que se han presentado y/o han derivado los descontentos son variadas. Aquí se debe aclarar que no se hace una distinción entre manifestaciones y causas o efectos de estas manifestaciones o del conflicto mismo, sino simplemente se hace alusión a hechos, acciones y/o eventos que se han presentado en el conflicto y que de alguna u otra forma han resultado importantes en el devenir del mismo, y que en algunos casos se pueden clasificar como de acciones directas, actos políticos, actos violentos e incluso estrategias de movilización legal. Tampoco se hace ninguna clasificación de las mismas, sino que sólo se enlistan en un sentido informativo de su presencia en los conflictos identificados. 
Cuadro 4. Formas de manifestación identificadas en los conflictos en torno al agua en México

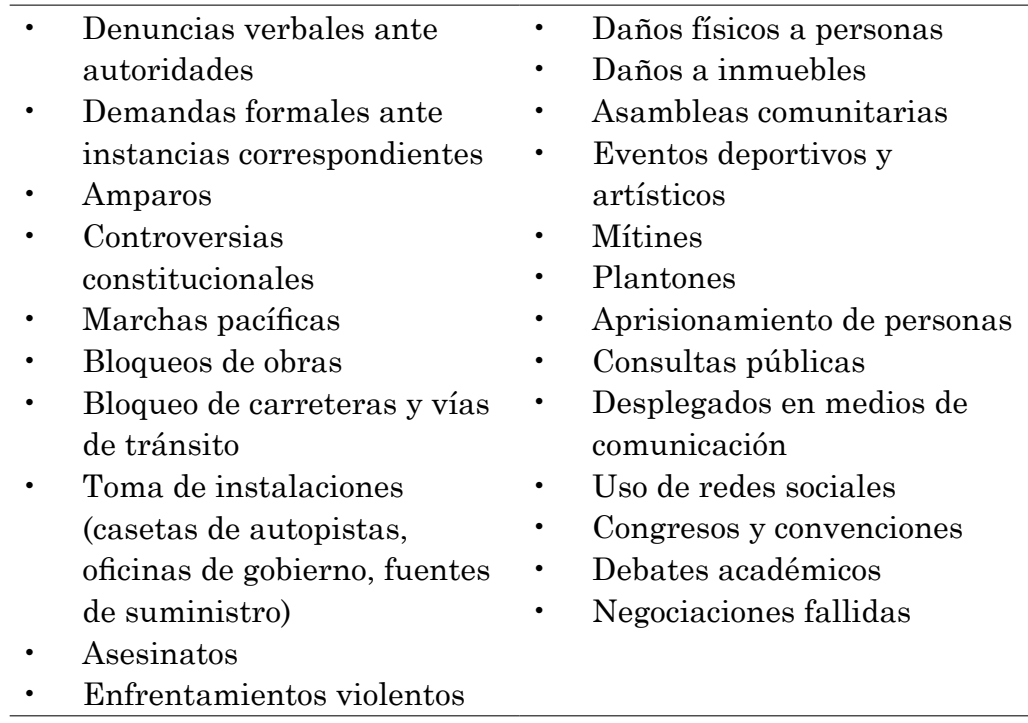

Fuente: elaboración propia con base en la metodología aplicada.

De esa manera, en el cuadro 4 se puede ver que dichas manifestaciones van desde un desplegado público, hasta asesinatos. Se encontró que en un alto número sí se han presentado actos violentos e incluso con lesiones de personas o daños a inmuebles. Algunas manifestaciones son muy creativas, como el caso de El Zapotillo, en el que se han compuesto canciones y poemas relacionados con la defensa de su causa; además, en el pueblo se han plasmado murales que dan muestra de la protesta. En otros casos la disputa se ha ido sólo por lo legal, presentando denuncias formales y/o solicitando amparos. También se dan los casos en los que se realizan plantones y/o bloqueos de instalaciones, vías de tránsito y obras. En el siguiente cuadro se enlistan las diversas formas de manifestación que se identificaron a partir del trabajo hemerográfico. 
Además de variadas, como se puede notar, las formas de manifestación son de distinta intensidad. Aunque no es regla, se encontró que en la mayoría de los casos se inicia con formas de manifestación de baja intensidad, como es el caso de denuncias verbales y desplegados en medios de comunicación, pero en la medida que no se da tratamiento adecuado a los conflictos (no se les hace caso, los procedimientos de negociación no son adecuados, entre otros fallos), éstos van escalando a manifestaciones de mayor intensidad como lo son los bloqueos o toma de instalaciones, enfrentamientos violentos con daños a personas e instalaciones, en algunos casos intentos de asesinato e incluso asesinatos.

\section{Duración o tiempo activo}

Un elemento importante en las características de un conflicto es el tiempo que lleva activo, ello debido a que entre más dura activo un conflicto, mayor es la posibilidad de que se agreguen actores y temas a debatir, y que las manifestaciones se intensifiquen, volviéndose incluso más complejo (Wolf et al., 2005; Loan, Hayward, Walnycki, Husseiki y Karlsson, 2017; Kaufman, Diep y Kaufman, 2019). Sin tener alguna lógica de clasificación en mente, solamente con la intención de mostrar diversos periodos de duración de los conflictos (que fueron conflictos que van desde los que tienen menos de un año activo y hasta 49 años), en la gráfica 4 se muestran diferentes rangos de tiempo y los porcentajes de conflictos clasificados en ellos. 
Gráfica 4. Duración de los conflictos en torno al agua en México

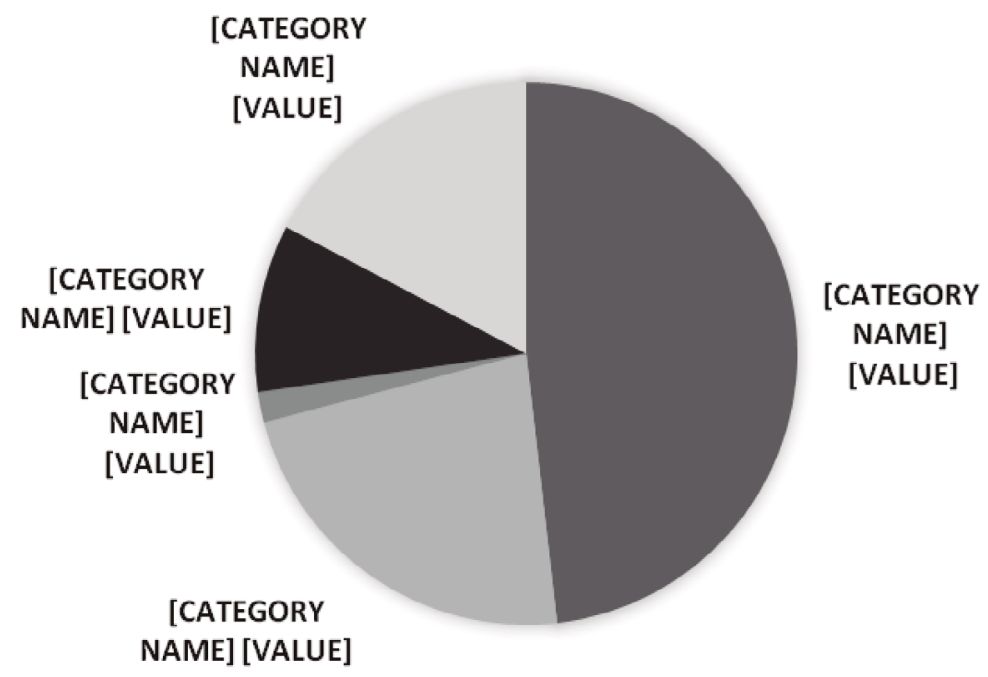

Fuente: elaboración propia con base en la metodología aplicada.

En la gráfica 4 se puede ver que más de la mitad de los casos lleva un año o menos activo (53\%). Otro 25\% lleva activo de dos a tres años, con lo que se puede resumir que casi $80 \%$ de los conflictos en torno al agua en México tienen activos tres o menos años, pudiéndose considerar que son de corto plazo. Sin embargo, eso también es para llamar la atención a que se dé tratamiento a esos conflictos antes de que escalen (aunque también se puede dar el caso de que por diversas razones algunos de ellos desaparezcan, ya sea que los solucionen o los terminen).

\section{Conclusiones y retos a futuro}

Este trabajo representa un esfuerzo más por avanzar en el estudio de los conflictos sociales en torno al agua en México, pues el fenómeno es amplio, creciente y complejo, de tal manera que los retos que se avecinan son tanto de

\section{2}


carácter empírico como teórico. Los aportes de este trabajo apuntan hacia una mayor sistematización y sofisticación de datos y fuentes de información respecto a los conflictos en torno al agua que existen en el país, a partir de la propuesta y aplicación de una metodología para la identificación y caracterización de conflictos en torno al agua; y a partir de los resultados obtenidos de la aplicación de la metodología propuesta, avanzar en su operacionalización estableciendo diversas categorizaciones que puedan ser retomadas en diversos estudios para al menos tener una aproximación mayor a su entendimiento y por lo tanto a su abordaje.

Visto así, empíricamente los resultados presentados muestran claramente que los conflictos subnacionales en torno al agua son un fenómeno de importante magnitud a lo largo del territorio nacional, estando presentes en prácticamente todos los estados de la República Mexicana. Además, aunque dichos resultados revelan la heterogeneidad de elementos que los caracterizan, fue posible resumir diversas características comunes en cuanto a sus fuentes, actores, manifestaciones, ubicación, duración, nivel de complejidad, entre otras, para su consideración en el diseño de estrategias flexibles para su prevención, resolución y/o tratamiento.

Finalmente, algunos de los retos y/o tareas futuras, además de avanzar en las limitaciones metodológicas, tanto de las fuentes de información como en el perfeccionamiento de la sistematización de datos, la definición, operacionalización e identificación de factores, también resulta relevante avanzar en la identificación de variables y/o factores asociados a este tipo de disputas, dando seguimiento temporal a su evolución, puesto que los casos aquí resumidos representan sólo la situación en un punto en el tiempo. 
Bibliografía

Agencia de Estados Unidos para el Desarrollo Internacional. (20I4). Water and conflict:A toolkit for programming. Washington: USAID.

Alba de, F. (2007). Geopolítica del agua en México: La oposición entre la hidropolítica y el conflicto sociopolítico. Los nuevos rostros de las "luchas" sociales. Interações. Revista Internacional de Desenvolvimiento Local, 8(I): 95-II2.

Amaya, M. (2007). Importancia de las instituciones en la gestión del agua.Ide@s Concyteg, núm. 28, pp. 704-7I 2. Recuperado de:http://www.laisumedu.org/desin_ibarra/ usuarios/amayaconcyteg.pdf

Autoridad Nacional del Agua de Perú. (2014). Protocolo para la prevención y gestión de los conflictos sociales vinculados con los recursos hídricos. Perú: ANAP.

Ávila, P. (2002). Cambio global y recursos hídricos en México: Hidropolítica y conflictos contemporáneos por el agua. México: Instituto Nacional de Ecología.

Bar-Tal, D. (2000). From intractable conflict through conflict resolution to reconciliation: Psychological analysis. Political Psychology, 2 I (2): 35 I-365.

Becerra, M., Sainz, J., y Muñoz. (2006). Los conflictos por agua en México. Diagnóstico y análisis. Gestión y Política Pública, 15(I): I I I-I43. Recuperado de: http:// gestionypoliticapublica.cide.edu/num_anteriores/Vol. XV_No.I_lersem/04Becerra.pdf

Berg, S. (2007). Conflict resolution: Benchmarking water utility performance. Public Administration and Development, 27(I): I- I I. doi: 10.1002/pad.437.

Buckles, D. (Ed.). (I999). Cultivating pace. Conflict and collaboration in natural resource management. Ottawa, Canadá: International Development Research Centre.

Caballero,V. (2009, agosto). Los conflictos sociales y socioambientales en el sector rural y su relación con el desarrollo rural. Notas para un balance de investigaciones. Trabajo 
presentado en el XIII Seminario Permanente de InvesBibliografía tigación Agraria, Cusco, Perú. Recuperado de: http:// www2.congreso.gob.pe/sicr/cendocbib/con3_uibd. nsf/7 I 267bc7fe0f83fa05257966007877e5/\$file/los_conflictos_sociales_y_socioambientales.pdf

Caldera, A. (20/2). Las ideas y el proceso político en las estrategias para hacer frente a la crisis del agua. Dos casos mexicanos. Revista de El Colegio de San Luis, nueva época, 2(4): 54-99. doi: 10.21696/rcs1042012532.

Castillo, D. (2008). El análisis sistémico de los conflictos ambientales: Complejidad y consenso para la administración de los recursos comunes. En Salamanca, M. (Coord.), Las prácticas de resolución de conflictos en América Latina (pp. 153-172). Bilbao, España: Instituto de Derechos Humanos de la Universidad de Deusto.

Center for Naval Analyses. (2017). The Role of Water Stress in Instability and Conflict. Estados Unidos: CNA.

Fernández-Jáuregui, C. (200I). El agua como fuente de conflictos: Repaso de los focos de conflictos en el mundo. Revista CIDOB d'Afers Internacionals, Pp. 45-46, I79-I 94. Recuperado en: https://dialnet.unirioja.es/servlet/articulo? codigo $=4739105$

Gleick, P., y Heberger, M. (20I4).Water and Conflict Events, Trends, and Analysis (20 I I-20 I 2). Water Brief, 8(3): I 59I7I.Recuperado en:http://worldwater.org/wp-content/ uploads/20 I 3/07/www8-water-conflict-events-trendsanalysis.pdf

Haftendorn, H. (2000). Water and International Conflict. Third World Quarterly, 2I(I): 5I-68. doi: 10.1080/0I4365900I3224.

Hernández, A. (2017). Análisis de vulnerabilidad hídrica al cambio climático. Sitio Piloto: La Paz, Baja California Sur, México. México: Unión Europea. 
Bibliografía
Herz, C. (20I I). Prevención y manejo de conflictos socioambientales. Serie Manuales, núm. 6. Perú: Ministerio Federal de Cooperación Económica y Desarrollo.

Huamani, G. (2006). Análisis de conflictos de agua en el Perú. Perú: Cooperación Holandesa para el Desarrollo.

Instituto Danés para Estudios Internacionales. (2006). Competencia por el agua: Entendiendo el conflicto y la cooperación en la gestión local del agua. Copenhague: Instituto Danés para Estudios Internacionales.

Jiménez, B.,y Torregrosa, M. (2007).Water services in Mexico: Are they a public priority? Journal of Comparative SocialWelfare, 23(2): I55-I65. doi: I0. I080/I748683070 I 494673. Kaufman, M., Diep, H., y Kaufman, S. (2019). Sociophysics of Intractable Conflicts:Three-Group Dynamics. Physica A: Statistical Mechanics and its Applications, 5 I 7(I): I75- 187. doi: 10.1016/j.physa.2018.I I.003.

Kreamer, D. (20I2). The Past, Present, and Future of Water Conflict and International Security. Journal of Contemporary Water Research \& Education, núm. I49, pp. 88-96. doi: I0. I I I I/j. I936-704X.20I2.03 I30.

Kriesberg, L. (20I6). Nature, dynamics, and phases of intractability. En Kriesberg, L. (Ed.), Louis Kriesberg: Pioneers in arts, humanities, science, engineering, practice (pp. 63-89). Nueva York, Springer.

Liber, M., y Bautista, J. (2015). Análisis, prevención y resolución de conflictos por el agua en América Latina y el Caribe. Chile: CEPAL, Serie Recursos naturales e infraestructura, núm. I7I.

Loan, D., Hayward,T.,Walnycki,A., Husseiki, M.,y Karlsson, L. (2017). Water, crises and conflict in Mena: How can water service providers improve their resilience? Working Paper. Inglaterra: International Institute for Environment and Development. 
Macassi, S., y Subauste, E. (2009). Tratamiento informativo y Bibliografía gestión periodística en los conflictos medioambientales. Perú: Embajada Británica.

Mestre, E. (2005). Cuencas en Latinoamérica: Perfiles y casos de organización y gestión ambiental y social. En Vargas, S.,y Mollard, E. (Eds.), Problemas socioambientales y experiencias organizativas en las cuencas de México (pp. 24-36). Morelos, México: Instituto Mexicano de Tecnología del Agua.

Mitchell, C. (2005). Resolving intractable conflicts:A handbook. Virginia, Estados Unidos: George Mason University.

Mollard, E.,Vargas, S., y Wester, P. (2010). Social Participation in Mexican River Basin Organizations:The Resilience of Coalitions. En Berry, K., y Mollard, E. (Eds.), Social Participation in Water Governance and Management. Critical and Global Perspectives (pp. I I 5- I 35). Londres: Earthscan. Monforte, G., y Cantú, P. (2009). Escenario del agua en México. Cultura Científica y Tecnológical/Recursos Hídricos (pp. 30-3I, 32-40). Recuperado de: http://erevistas.uacj. $\mathrm{mx} /$ ojs/index.php/culcyt/article/view/356/336

Moore, S. (2018). The Water Wars Within: Preventing Sub-national Water Conflict. New Security Beat. Recuperado de: https://www.newsecuritybeat.org/2018/05/ water-wars-within-preventing

Munk, H. (2004). Water and conflict prevention and mitigation in water resources management. DIIs Report, núm. 2. Copenhague, Dinamarca: Instituto Danés para Estudios Internacionales.

Musseta, P. (2010). Los conflictos por agua en América Latina. Documento de trabajo 2. México: Instituto Tecnológico Autónomo de México-Centro de Estudios y Programas Iberoamericanos.

Mustafa, D. (2007). Social construction of hydro politics: The geographical scales of water and security in the 
Bibliografía
Indus basin. The Geographical Review, 97(4):484-30 I. doi: I0.1 I I I/j. I 93 I-0846.2007.tb00408.

Nandalal, K., y Simonovic, S. (2003). Resolving conflicts in water sharing: A systemic approach. Water Resources Research, 39(12): 13-62. doi: 10.1029/2003WR002 I 72. Pacheco, R. (20I3). Los conflictos intratables por el agua en México: Aproximaciones teóricas y acercamientos metodológicos. En Kauffer, E. (Ed.), Taller temático “Las dimensiones políticas de los recursos hídricos: Miradas cruzadas para politizar el debate" (pp. I-30). Chiapas, México: Centro de Investigaciones y Estudios Superiores en Antropología Social.

. (20I4). Conflictos intratables por el agua en México: Aplicando el recorte analítico de intratabilidad,"enmarcamiento y reenmarcamiento". En De Alba, F., y Amaya, L. (Eds.), Estado y ciudadanía del agua: Cómo significar las nuevas relaciones (pp. 279-317). México: Universidad Autónoma Metropolitana.

Perevochtchikova, M. (20I0). La problemática del agua: Revisión de la situación actual desde una perspectiva ambiental. En Lezama, J., y Graizbord, B. (Coords.), Los grandes problemas de México: Iv, Medio ambiente (pp. 6I-104). México: El Colegio de México.

Pettersson, H. (201 I). Intractability of conflict. Causes, drivers and dynamics of the war in Somalia. Tesis de maestría. Recuperada de https://core.ac.uk/download/ pdf/37326I60.pdf

Reforma. (2015). La guerra del agua. Revista Reforma, núm. 64. Restrepo, I. (20I5). El conflicto por el agua. La Jornada. Recuperado de http://www.jornada.unam.mx/2015/0I/05/ opinion/0I8a2pol

Rodríguez, C. (20I2). Conflictos por el aprovechamiento y control del agua de comunidades rurales en la zona central de México. Proceso de producción del conocimiento.Avance de investigación en curso Grupo deTrabajo I5:Medio ambiente, 
sociedad y desarrollo sustentable. México: UAM-Xochimilco. Recuperado de: http://actacientifica.servicioit.cl/biblioteca/gt/gt I5/gt I5_rodriguezwallenius.pdf

-. (2013). Campesinos, agua y despojo. Resistencias frente a la mercantilización del agua por parte de empresas y gobiernos en la zona central de México. Textual, núm. 62, pp. 75-97. Recuperado de: https://www.chapingo.

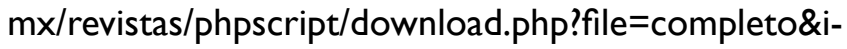
$\mathrm{d}=$ MjYymq $==$

Ruiz, R. (2016). Prevención y resolución de conflictos en torno al agua ante la construcción de obras hídricas: Un caso de negación de agenda en México. Gestión y Análisis de Políticas Públicas. Nueva Época, 2(16). doi:http://dx.doi. org/l 0.24965/gapp.v0il6.10365

Santacruz, G. (20I2). Conflictos sociales por el uso del agua en la cuenca del Río Valles, Huasteca, México (19001945). Revista de El Colegio de San Luis, nueva época, 2(4): 102-I29. doi: I0.21696/rcsI0420I253I.

Schlager, E., y Heikkila,T. (2009). Resolving water conflicts:A comparative analysis of interstate river compacts. The Policy Studies Journal, 37(3):367-392. doi: I0. I I I I/j. I54 I0072.2009.00319.x.

Selby, J. (2005). Oil and Water:The Contrasting Anatomies of Resource Conflicts. Government and Opposition, 40(2): 200-224. doi: I0.1 I I I/j. I477-7053.2005.00I50.x.

Stetter, S., Herschinger, E., Teichler, T., y Albert, M. (20I I). Conflicts about water: Securitizations in a global context. Cooperation and Conflict, 46(4): 44I-459. doi: I0.1 I77/00I08367| I 422462.

Thomas, T. (2017). The "Mundane Violence" of International Water Conficts. Education About Asia, 22(2): 36-4I.

Toledo, V., Garrido, D., y Barrera, N. (20I4). Conflictos socio-ambientales, resistencias ciudadanas y violencia neoliberal en México. Ecología Política Cuadernos de Debate Internacional, núm. 46, pp. II 5-I 24. 
Bibliografía

Vallacher, R., Coleman, P., Nowak, A., y Bui-Wrzosinska, L. (2010). Rethinking Intractable Conflict:The Perspective of Dynamical Systems. American Psychologist, 65(4): 262278. doi: I0.1037/a001 9290.

Vargas, S. (2013). Prevención de conflictos y cooperación en la gestión de los recursos hídricos en México. México: Instituto Mexicano de Tecnologías del Agua.

Vargas, S., y Mollard, E. (2004, octubre). Conflictos ambientales en la gestión del agua en México. Ponencia presentada en el xxv International Congress of Latin American Studies Association, Las Vegas, EUA. Recuperado de: https:// www.researchgate.net/publication/268407 I 9I_conflictos_ambientales_en_la_gestion_del_agua_en_mexico Wolf,A., Kramer,A., Carius,A.,y Dabelko, G. (2005). Gestionando conflictos por el agua y cooperación. En Renner, M., French, H.,yAssadourian, E. (Coords.), La situación del mundo 2005: Redefiniendo la seguridad mundial. Informe anual delWorldwatch Institute sobre el progreso hacia una sociedad sostenible (pp. I55- I78). Barcelona: Centro de Investigación para la Paz.

World Wildlife Fund. (2012). Water Conflict: Myth or Reality? Suiza: WWF.

Yoffe, S., Fiske, G., Giordano, M., Giordano, M., Larson, K., Stahl, K., y Wolf, A. (2004). Geography of international water conflict and cooperation: Data sets and applications. Water Resources Research, 40(5). Recuperado de: https://asu.pure.elsevier.com/en/publications/ geography-of-international-water-conflict-and-cooperation-data-se 